\title{
Pediatric practice based evaluation of the Steps to Prevent Firearm Injury program
}

\author{
Pamela J Oatis, Nancy M Fenn Buderer, Peter Cummings, Rosemarie Fleitz
}

Department of Pediatrics, St Vincent Mercy Medical Center, Toledo, Ohio P J Oatis

Research Department, St Vincent Mercy Medical Center, Toledo, Ohio N M Fenn Buderer

Department of Epidemiology, University of Washington School of Public Health and Community Medicine and Harborview Injury Prevention and

Research Center, Seattle, Washington P Cummings

Pediatric Clinic, St Vincent Mercy Medical Center, Toledo, Ohio R Fleitz

Correspondence and reprint requests to: Dr Pamela Oatis, St Vincent Family Care Center, 2213 Franklin

Avenue, Toledo, $\mathrm{OH} 43620$, USA.

\begin{abstract}
Objective-To estimate the prevalence of gun ownership and methods of gun storage in homes of pediatric patients before and after an educational intervention.

Design-Before and after trial.

Setting-Hospital based, inner city, pediatric primary care practice.

Participants-Consecutive sample of parents of patients with appointments August to November 1994.

Intervention-Before the intervention, participants completed an anonymous questionnaire regarding ownership and storage of guns in their home. The intervention followed the Steps to Prevent Firearm Injury program of the American Academy of Pediatrics. It began after the parent completed the questionnaire and was reinforced at subsequent visits until July 1995. Families completing a baseline questionnaire and returning to the office July to October 1995 were resurveyed. Main outcome measure-Reported change in gun ownership and methods of storage. Results-A gun(s) in the home was reported by $8.7 \%$ of respondents. Matched baseline and follow up questionnaires were available for $23.6 \%$ of families. In these, gun ownership reportedly decreased after intervention from $9.4 \%$ to $7.0 \%$, handgun ownership fell from $5.4 \%$ to $3.0 \%$, and long gun ownership fell from $6.1 \%$ to $5.5 \%$. Storing guns outside of a locked container did not change from the baseline prevalence of $2.7 \%$, but keeping any gun loaded fell from $1.6 \%$ to $0.5 \%$. All $p$ values were $>0.05$.

Conclusion-This study was unable to demonstrate a statistically significant decline in gun ownership or improvement in gun storage after a practice based intervention designed to encourage these behaviors.

(Injury Prevention 1999;5:48-52)
\end{abstract}

Keywords: firearms; prevalence; intervention study

Injury and death due to guns is a significant problem for youth internationally, especially in the United States. In a study of 26 industrialized nations that reported firearm related deaths among children age $0-14$ years, for one year during 1990-95, the overall United States firearm related death rate was almost 12 times higher than that of the other 25 countries combined-1.66 deaths per 100000 children compared with $0.14{ }^{1}$
In the United States, guns in the home are common, including 66 million handguns. ${ }^{2}{ }^{3}$ Guns in the home have been associated with unintentional deaths when young children play with loaded firearms, ${ }^{4-6}$ with an increased risk of adolescent suicide, ${ }^{7-9}$ and with homicide. ${ }^{10}$ During an average day in 1995, 2.3 children in the United States under the age of 15 years died from gunshot wounds; and 26.8 died each day in the 15-24 year old age group. ${ }^{11}$ More 15-19 year old males died of gunshot wounds than any natural cause. ${ }^{12} 13$ If current trends continue, guns may kill more youth in the United States than motor vehicle accidents. ${ }^{14}$ Adolescent African-American males have especially high firearm related mortality rates. ${ }^{15}$

Physician counseling has been shown to be effective in some types of injury prevention, though its application regarding firearm safety has not yet been examined. ${ }^{16}$ The American Academy of Pediatrics (AAP), and its Committee on Adolescence and Committee on Injury and Poison Prevention, have made recommendations on regulatory measures, education, and research regarding firearm related injuries. ${ }^{71}{ }^{18}$ In 1994, the AAP, in conjunction with the Center to Prevent Handgun Violence, initiated a program called Steps to Prevent Firearm Injury, or STOP. ${ }^{12}$ This program included materials to be used in a pediatrician's office as part of anticipatory guidance for firearm safety.

This study is the first to examine the prevalence of gun ownership and methods of gun storage in homes of pediatric patients before and after the STOP educational intervention to promote safe gun storage.

\section{Methods}

The study design was a before and after trial conducted in a midwest, hospital based, urban, low income, eight member group pediatric practice with 19000 annual visits. At the time of the study, the office's patient population was $70 \%$ African-American, $23 \%$ white, $6 \%$ Hispanic, and $1 \%$ other. Ninety per cent of patients were low income (on Medicaid). A consecutive sample of parents of patients seen between August and November 1994 were asked to participate.

An anonymous questionnaire was developed to gather information about respondents, their households, the presence and number of handguns and long guns in the home (referred to hereafter as gun ownership), and the methods of gun storage. The questionnaire was assessed for face and content validity. A pilot study of 25 
patients was conducted to examine their understanding of the questions and instructions.

From August through November 1994, when many families come to their pediatrician for annual school physicals, all caretakers (usually parents or relatives) of children who visited the office were asked to participate. Upon check-in, parents were asked to complete the questionnaire before seeing the doctor. For each patient enrolled, identical identification numbers were written on two questionnairesthe first (baseline) was given to the parent and the second (follow up) was placed in the patient's chart. When the patient returned during the follow up phase, the parent was asked to complete the second questionnaire. Through this process, baseline and follow up questionnaires were matched and the family's anonymity was maintained.

Physicians, nurses, aids, and clerks were instructed by the investigators before the educational intervention. All were told the goal was to have families remove guns from the home if possible, or to store guns safely if removal was impossible. They all received a script of what to say to parents and patients and handout materials were readily available.

The intervention began with the baseline appointment and was reinforced on subsequent visits until July 1995. The timing and frequency of subsequent visits was determined by the parent and physician as needed for the care of the child, not for study purposes. The standardized anticipatory guidance followed the AAPs' STOP program..$^{12}$ Pediatricians and nurses discussed the dangers of having a gun in the home and they advised families to eliminate guns from the home or to store them unloaded and locked. Pediatricians and nurses were blinded to the parents' responses. All families

Table 1 Characteristics of households responding to baseline questionnaire, including gun ownership and storage ( $n=1617$ households)

\begin{tabular}{lc}
\hline & Median (range $)^{\star}$ or No (\%) \\
\hline Age of respondent (years) & $27(10-76)^{\star}$ \\
Age of youngest child (years) & $2(0-17)^{\star}$ \\
No of residents & $4(0-16)^{\star}$ \\
No of children & $2(0-12)^{\star}$ \\
Female respondent & $1474(92.7)$ \\
At least one adult male in the home & $770(49.0)$ \\
Someone who lives in the home has been shot & $94(5.9)$ \\
Visitors come to the home with guns & $38(2.4)$ \\
Gun ownership and storage & \\
Any gun in the home & $139(8.7)$ \\
One or more handguns & $96(6.4)$ \\
One or more long guns & $77(5.2)$ \\
Any gun not stored in a locked container or locked cupboard & $36(2.3)$ \\
Any gun stored loaded & $30(1.9)$ \\
\hline
\end{tabular}

Table 2 Univariate associations between baseline characteristics and gun ownership

\begin{tabular}{llll}
\hline Characteristic & Crude OR & 95\% CI & p Value \\
\hline Age of respondent (years) & 1.04 & 1.02 to 1.06 & $<0.001$ \\
Age of youngest child (years) & 1.06 & 1.01 to 1.10 & 0.01 \\
No of residents & 1.01 & 0.92 to 1.11 & 0.8 \\
No of children & 0.84 & 0.74 to 0.96 & 0.01 \\
At least one adult male in the home & 5.10 & 3.26 to 7.97 & $<0.001$ \\
Someone who lives in the home has been shot & 1.29 & 0.65 to 2.56 & 0.5 \\
Visitors come to the home with guns & 4.00 & 1.89 to 8.47 & $<0.001$ \\
\end{tabular}

$\star$ The odds of owning a gun among households with the characteristic compared with the odds of owning among those without that characteristic. For continuous characteristics (for example age of respondent), the OR is the change in odds of ownership associated with a one unit (for example one year) increase in the characteristic. received the intervention, regardless of whether they completed the questionnaire.

Written materials were distributed at each visit. Materials included: a STOP brochure; a coloring book emphasizing that guns are not toys and should not be touched; and a handout, with pictures of persons disposing of guns or storing them unloaded and locked. On 1 December 1994 (after all the baseline questionnaires were completed), 30 STOP posters with messages urging disposal or proper gun storage were prominently displayed throughout the office. Thus, all families were exposed to these messages.

From July through October 1995, when we anticipated the largest proportion of families would return to the office for annual school physicals, posters and educational materials were removed from the office and counseling about firearms ceased. Parents who completed a baseline questionnaire and who returned during these four months were asked to complete the follow up questionnaire.

This research was approved by the St Vincent Mercy Medical Center Human Experimentation and Medical Staff Research Committees (that is, Institutional Review Board).

ANALYSES

Data are presented as numbers or medians, with some missing data for all items. Univariate associations between baseline characteristics and gun ownership were examined using the odds ratio (OR) and $\chi^{2}$ statistics, and presented with the $95 \%$ confidence interval (CI). ${ }^{19}$ For each baseline characteristic, potential confounding by other characteristics was examined with logistic regression. ${ }^{20}{ }^{21}$ Comparisons of respondents with and without a follow up questionnaire were made. McNemar's test was used to compare gun ownership and storage before and after education; exact $\mathrm{p}$ values are reported. ${ }^{21} 22$ To test whether the effect of the intervention program differed by whether or not there was an adult male in the household, exact conditional logistic regression was used. $^{2023}$ All $\mathrm{p}$ values are two sided, with $\mathrm{p}$ value $<0.05$ considered statistically significant.

\section{Results}

There were 1617 baseline questionnaires completed by respondents with a median age of 27 years, $92.7 \%$ of whom were women (table 1 ). A gun(s) in the home was reported by $8.7 \%$ of respondents.

Univariate analyses included 1588 questionnaires. Excluded were 13 respondents who did not know if there was a gun in the home and 16 with missing data on gun ownership. Respondents who reported a gun in the home were significantly older than non-gun owners, had older children, and fewer children at home (table 2). Gun owners were more likely to have at least one adult male living in the home $(81.3 \%$ v $46.1 \%)$, and were more likely to report that visitors come to their home with guns $(7.6 \% v 2.0 \%)$. The number of residents in the home, and a history that someone living 
Table 3 Comparison of respondents who had a follow up questionnaire with respondents who had only a baseline questionnaire

\begin{tabular}{llll}
\hline Characteristic & $\begin{array}{l}\text { Baseline and } \\
\text { follow up }(n=381)\end{array}$ & $\begin{array}{l}\text { Baseline only } \\
(n=1236)\end{array}$ & p Value* \\
\hline Age of respondent (years) & $\begin{array}{l}\text { Median (range) } \\
27(10-69)\end{array}$ & $\begin{array}{l}\text { Median (range) } \\
26(10-76)\end{array}$ & 0.6 \\
Age of youngest child (years) & $1.2(0-17)$ & $2.0(0-17)$ & $<0.001$ \\
No of residents & $4(1-12)$ & $4(1-16)$ & 1.0 \\
No of children & $2(0-9)$ & $2(0-11)$ & 0.2 \\
& No(\%) & No (\%) & \\
Female respondent & $356(94.4)$ & $1117(92.2)$ & 0.2 \\
At least one adult male in the home & $189(51.2)$ & $572(48.5)$ & 0.4 \\
Someone who lives in the home has been shot & $17(4.6)$ & $77(6.4)$ & 0.2 \\
Visitors come to the home with guns & $8(2.2)$ & $30(2.5)$ & 0.6 \\
Gun ownership and storage & $36(9.7)$ & $103(8.5)$ & 0.5 \\
$\quad$ Any gun in the home & $19(5.3)$ & $77(6.8)$ & 0.3 \\
$\quad$ One or more handguns & $21(5.9)$ & $56(4.9)$ & 0.5 \\
One or more long guns & $11(2.9)$ & $25(2.1)$ & 0.3 \\
Any gun not stored in a locked container or & & $22(1.8)$ & 0.7 \\
$\quad$ locked cupboard & $8(2.1)$ & & \\
Any gun stored loaded & & 22 & \\
\hline
\end{tabular}

^ Mann-Whitney-Wilcoxon test; $\chi^{2}$ or Fisher's exact test.

Table 4 Changes in gun ownership and storage among 381 respondents with baseline and follow up questionnaires

\begin{tabular}{lccc}
\hline Characteristic & $\begin{array}{l}\text { No(\%) } \\
\text { baseline }\end{array}$ & $\begin{array}{l}\text { No (\%) } \\
\text { follow up }\end{array}$ & p Value* \\
\hline Any gun in the home & $35(9.4)$ & $26(7.0)$ & 0.1 \\
One or more handguns & $18(5.4)$ & $10(3.0)$ & 0.1 \\
One or more long guns & $20(6.1)$ & $18(5.5)$ & 0.8 \\
$\begin{array}{l}\text { Any gun not stored in a locked container or } \\
\quad \text { locked cupboard }\end{array}$ & $10(2.7)$ & $10(2.7)$ & 1.0 \\
Any gun stored loaded & $6(1.6)$ & $2(0.5)$ & 0.3 \\
\hline
\end{tabular}

* McNemar exact $\mathrm{p}$ value. result of the low prevalence of gun ownership in the study population and low rate of follow up. The sample size requirement estimated before the study began was based on the following assumptions: $50 \%$ prevalence of gun ownership at baseline and $45 \%$ at follow up; $5 \%$ to $10 \%$ of non-gun owners become owners; $15 \%$ to $20 \%$ of owners become non-owners. To ensure $80 \%$ power to detect a true difference with $5 \%$ type I error, we needed between 288 and 436 families with follow up, and we obtained data from 381 families. However, the prevalence of gun ownership that we observed was much lower than we had anticipated. If we assume that the values we observed for gun ownership before and after the intervention were exactly reproduced in a larger study, then that study would need in excess of 620 families for the difference to be statistically significant; and a larger number of families would be needed to have $80 \%$ power of detecting such a difference in a planned study. Post hoc power calculations, however, should be treated with caution, since we can never know what the distribution of outcomes would have been had our study been larger. ${ }^{24}$

Nearly $9 \%$ of the families reported having a gun in the home. Given the frequency of gun related violence in urban settings, this prevalence seems low. It is substantially lower than a 1994 national survey reporting guns in 35\% of United States households. ${ }^{3}$ However, our households were not nationally representative; $51 \%$ had no adult male in the home, and most were urban and low income. The prevalence of gun ownership in this study was similar to that of other studies among low income households without adult males. A Seattle survey of gun ownership in four urban pediatric clinics, with 510 respondents, reported $9 \%$ of single adult homes (females were heads of household in $90 \%$ ) had a gun, compared with $31 \%$ among households that included a male non-spouse and $24 \%$ among those with a male spouse. ${ }^{25}$ Another study showed that among households with no adult male $12.9 \%$ owned a gun compared with $33.6 \%$ of households that included an adult male. ${ }^{26}$

Among the gun owning households, 26\% reported that at least one gun was not stored in a locked container or cupboard, and 22\% reported one or more guns were stored loaded. These figures were comparable with the findings of a national random telephone survey in which $21 \%$ of gun owners reported a firearm both loaded and unlocked in the home. ${ }^{27}$ Another survey of 1682 gun owning parents in 29 pediatric offices found $15 \%$ of gun owners reported at least one gun stored loaded in the home, and $7 \%$ reported an unlocked and loaded gun. ${ }^{28}$

Gun ownership was reported more often by families with an adult male, but the adult who received the intervention was usually the child's mother (or female parent). We hypothesized, therefore, that the intervention might have had a stronger effect when there was no adult male in the home, because the intervention in these homes was most likely directed towards the actual owner of the gun, the child's

Alternatively, it is possible that we failed to detect statistically significant changes because of the low statistical power of our study, as a 
mother. We found no support for this hypothesis. Homes with an adult male were actually more likely to give up a gun (results not shown), and a statistical test for a difference in intervention effect, according to whether or not there was an adult male in the home, was not statistically significant (exact mid $\mathrm{p}$ value $=$ 0.1 ). It is possible that female respondents were less likely to report a gun in the home than male respondents. Our data support this conjecture in the following way. In the 733 homes having at least one adult female and one adult male, $24 \%$ of male respondents reported a gun in the home compared with $13 \%$ of female respondents.

Physicians, nurses, aids, and clerks consistently delivered the intervention. During regular monthly meetings, staff were reminded of the intervention and enthusiasm persisted among the health care providers. Staff reported that overall families were receptive to the intervention. In focus groups after the study with the investigators and a small number of respondents, families expressed appreciation for the guidance from doctors and nurses. They were impressed that the office addressed the problem of guns. Only a few parents remarked that the topic was inappropriate for the physicians and nurses to discuss with them in the office.

\section{LIMITATIONS}

Our study lacked a control group which did not receive the intervention. Our original study plan was to collect similar baseline and follow up data in another practice that saw similar patients but did not offer any advice about firearms. That practice, however, failed to collect the needed data.

Respondents may have feared repercussions if they admitted owning a gun or storing a loaded gun. However, the baseline data were collected before any intervention. Furthermore, the surveys were anonymous. In addition, two previous studies suggest that most gun owners are willing to acknowledge their ownership. Kellermann et al performed inperson interviews with persons who had recently registered a gun purchase in Memphis or Seattle. Among 35 persons who consented to an interview about home safety, only one denied that a gun was kept in the home. ${ }^{29}$ Rafferty et al conducted a phone survey among a random sample of rural Michigan residents who had purchased a hunting license or registered a handgun; $87.3 \%$ of handgun registrants and $89.7 \%$ of hunting license owners reported keeping a gun in their household. ${ }^{30}$

After the intervention, some respondents might have felt even more reluctant to acknowledge gun ownership and unsafe storage practices, because the counseling made it clear that the medical providers disapproved of guns in the home. If this occurred, then this would have exaggerated any effect of the intervention. This bias does not explain our failure to find any statistically significant effect of the intervention.

We had follow up for $23.6 \%$ of the families that filled out a baseline survey. This was not surprising for two reasons. In our office, about $25 \%$ to $35 \%$ of patients fail to keep their scheduled appointments. Second, many families in the study clinic do not need care so often that they would be expected to appear during the four month period allotted for the collection of follow up information. Follow up only occurred if care was needed for a new problem or if a visit was scheduled for medical reasons. The families with follow up had younger children than those without follow up (table 3), and younger children are expected to be taken to the doctor more frequently for check-ups, colds, etc than older children. Our finding that those who were seen in follow up differed very little from those not seen (table 3), suggests that the group seen in follow up fairly represents the gun ownership and storage practices of all who received the intervention.

\section{Implications for prevention}

We were unable to demonstrate that a six month, practice based, educational intervention using the STOP program significantly reduced gun ownership or improved gun storage practices in the study households. Physician time is valuable and should be devoted to interventions that have been shown to work. ${ }^{31}$ Based on the available data, we can not recommend the STOP program.

The authors would like to express their thanks to the St Vincent Family Care Center pediatric staff for their enthusiasm and cooperation in conducting this research; to Angela C Lust for data entry; to Brenda Coon for manuscript preparation; and to data entry; to Brenda Coon for manuscript preparation; and to
Lisa Nichols of the St Vincent Mercy Medical Center library. This study was funded by St Vincent Mercy Medical Center This study was funded by St Vincent Mercy Medical Center
and research grant number 151 from the F M Douglass Founand research grant num
dation, Toledo, Ohio.

1 Krug EG, Dahlberg LL, Powell KE. Childhood homicide, suicide, and firearm deaths: an international comparison. World Health Stat $Q 1996 ; 49$ (4).

2 Department of the Treasury, Bureau of Alcohol, Tobacco, and Firearms. ATF news. Washington, DC: Department of the Treasury, Bureau of Alcohol, Tobacco, and Firearms, 1991 May 22. (Publication FY-91-36.)

3 Cook PJ, Ludwig J. Guns in America: national survey on private ownership and use of firearms. Research in brief. Washington, DC: National Institute of Justice, May 1997: Washingt 12 .

4 Beaver BL, Moore VL, Peclet M, et al. Characteristics of pediatric firearm fatalities. F Pediatr Surg 1990;25:97-100. 5 Martin JR, Sklar DP, McFeeley P. Accidental firearm fatalities among New Mexico children. Ann Emerg Med 1991;20:58-61.

6 Wintemute GJ, Teret SP, Kraus JF, et al. When children shoot children: 88 unintentional deaths in California. FAMA 1987;257:3107-9.

7 Committee on Adolescence. Firearms and adolescents. Pediatrics 1992;89:784-7.

8 Brent DA, Perper JA, Allman CJ, et al. The presence and accessibility of firearms in the homes of adolescent suicides: a case-control study. $\mathscr{7} A M A$ 1991;266:2989-95.

9 Kellermann AL, Rivara FP, Somes G, et al. Suicide in the home in relation to gun ownership. $N$ Engl $f$ Med 1992;327:467-72.

10 Kellermann AL, Rivara FP, Rushforth NB, et al. Gun ownership as a risk factor for homicide in the home. N Engl $f$ Med 1993;329:1084-91.

11 Anderson RN, Kochanek KD, Murphy SL. Report of final mortality statistics, 1995. Monthly vital statistics report: final data from the CDC. Hyattsville, MD: US Department of Health and Human Services, Centers for Disease Control and Prevention, National Center for Health Statistics, 1997;45(11 suppl 2):1-80.

12 American Academy of Pediatrics, Center to Prevent Handgun Violence. STOP: steps to prevent firearm injury. Elk Grove Village, IL: American Academy of Pediatrics, Center to Prevent Handgun Violence, 1994.

13 Spence A. Family instability leaves children vulnerable. $A A P$ news. Elk Grove Village, IL: American Academy of Pediatrics, Aug 1995: 8-12.

14 US Department of Health and Human Services, Public Health Service, Centers for Disease Control and Prevention. Deaths resulting from firearm and motor vehicle- 
related injuries-United States, 1968-1991. Morb Mortal Wkly Rep 1994;43(3):37-42.

15 Fingerhut LA. Firearm morality among children, youth, and young adults $1-34$ years of age, trends and current status: United States, 1985-90. Advance data: from vital and health statistics of the CDC. Hyattsville, MD. US Department of Health and Human Services, Public Health Service, Centers for Disease Control and Prevention, National Center for Health Statistics, 1993;231:1-20.

16 Bass JL, Kaufer Christoffel K, Widome M, et al. Childhood injury prevention counseling in primary care settings: critical review of the literature. Pediatrics 1993;92:544-50.

17 Committee on Injury and Poison Prevention. Firearm injuries affecting the pediatric population. Pediatrics $1992 ; 89$. 788-90.

18 Spivak H, Harvey B. The role of the pediatrician in violence prevention. Pediatrics 1994:94(4 suppl pt 2 of 2).

19 SAS Institute Inc. SAS/STAT user's guide, version 6. 4th Ed. Cary, NC: SAS Institute Inc, 1990;2:1071-126.

20 Breslow NE, Day ND. Statistical methods in cancer research, vol I: the analysis of case-control studies. Lyon, France: Intervol I: the analysis of case-control studies. Lyon, France: Inter-

21 Altman DG. Practical statistics for medical research. New York, NY: Chapman and Hall, 1991: 194-7, 239-41, 250-7, 266-9, 351-8.

22 Mehta C, Patel N. StatXact 3 for Windows: statistical software for exact nonparametric inference. User manual. Cambridge, MA: CYTEL Software Corporation, 1995: 189-92.
23 Mehta C, Patel N. LogXact for Windows: logistic regression software featuring exact methods. User manual. Cambridge, MA: CYTEL Software Corporation, 1996: 133-7.

24 Goodman SN, Berlin JA. The use of predicted confidence intervals when planning experiments and the misuse of power when interpreting results. Ann Intern Med 1994;121: 200-6.

25 Haught K, Grossman D, Connell F. Parents' attitudes toward firearm injury prevention counseling in urban pediatric clinics. Pediatrics 1995;96:649-53.

26 Senturia YD, Kaufer Christoffel K, Donovan M. Children's household exposure to guns: a pediatric practice-based survey. Pediatrics $1994 ; 93: 469-75$.

27 Hemenway D, Solnick S, Azrael D. Firearm training and storage. ҒAMA 1995;273:46-50.

28 Senturia YD, Kaufer Christoffel K, Donovan M. Gun storage patterns in US homes with children. Arch Pediatr Adolesc Med 1996;150:265-9.

29 Kellermann AL, Rivara FP, Banton J, et al. Validating survey responses to questions about gun ownership among owners registered handguns. Am f Epidemiol 1990;131:1080-4. 30 Rafferty AP, Thrush JC, Smith PK, et al. Validity of a household gun question in a telephone survey. Public Health Rep $1995 ; 110: 282-8$

31 US Preventive Services Task Force. Guide to clinical preventive services. 2nd Ed. Baltimore, MD: Williams and Wilkins, 1996

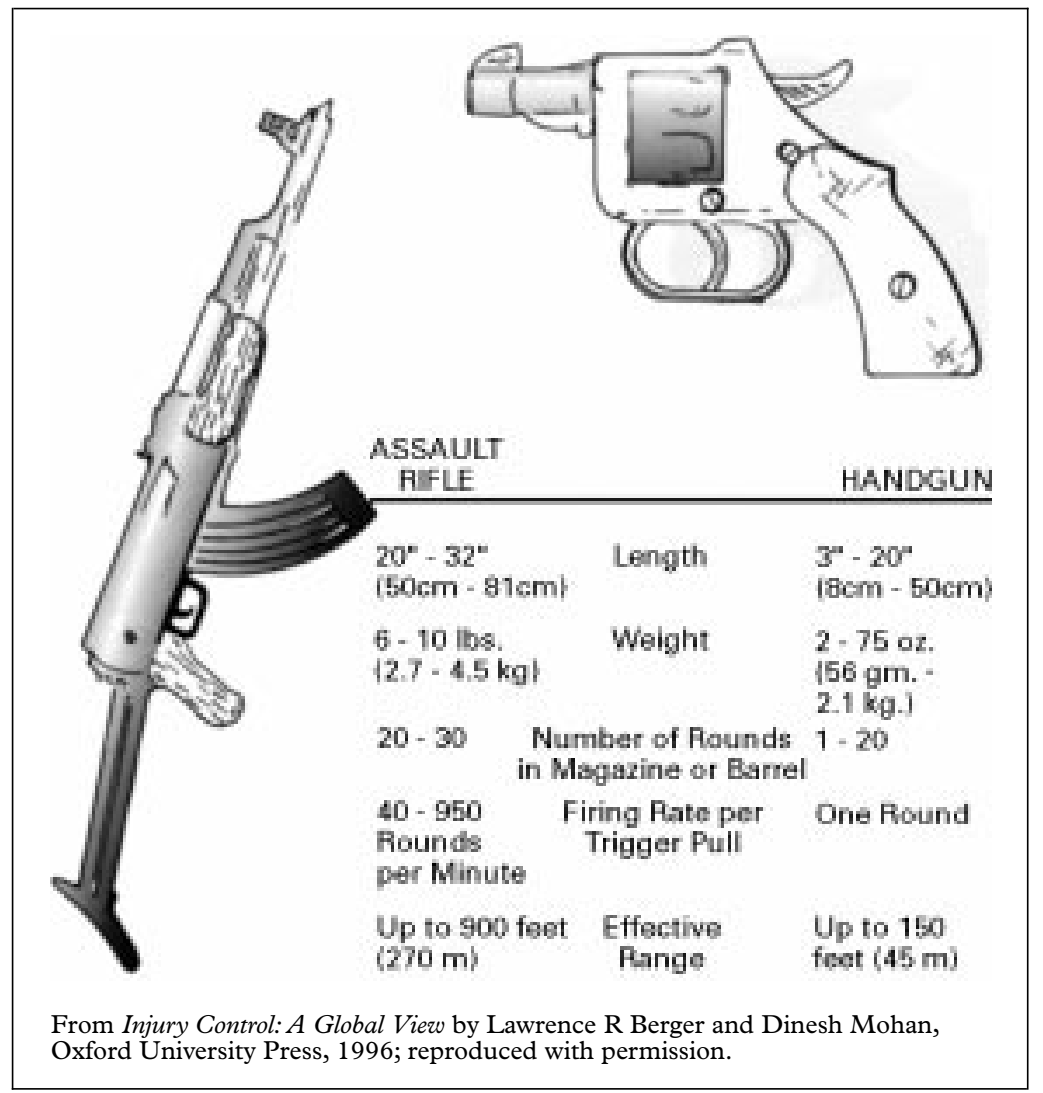

